\title{
Risk Factors of Burst Abdomen in Emergency Laparotomy
}

\section{${ }^{*}$ Rashid MHA ${ }^{1}$, Shaha $L K^{2}$, Shashi SS ${ }^{3}$, Faruk $I^{4}$}

\begin{abstract}
Burst Abdomen is a preventable condition in which many risk factors play their role and lead to life threatening complications. This study was carried out to find out various risk factors of burst abdomen following emergency laparotomy, to find out the high risk group of patients for burst abdomen, to determine the predictors of burst abdomen, to prevent the rate of burst abdomen \& find out morbidity and mortality of burst abdomen. This cross sectional study was done among 100 cases of burst abdomen occurring in Sir Salimullah Medical College \& Mitford Hospital, Dhaka and Dhaka Medical college, Dhaka during the period of July,2011 to December,2011. The patients were admitted for various surgical problems and underwent emergency laparotomy. Burst abdomen was taken into account. Another group of 100 patients who undergone emergency laparotomy but did not develop burst abdomen were also taken into account to make a comparison with the burst group. Patients who undergone elective laparotomy,paediatric age group,patients undergone exploration through mini laparotomy or transverse incision, patients with pregnancy were excluded from the study populations.Patients were assessed by history taking, examination and appropriate investigation before surgery and observed post operatively for any complication. The results were prepared on 100 patients underwent emergency laparotomy in SSMCMH \& DMCH.
\end{abstract}

Burst abdomen following emergency laparotomy results from multifactorial causes. The main outcome measure found significant as the risk factors of burst abdomen in this study were peritonitis (95\%), anaemia (26\%), malnutrition (18\%), in the preoperative period; inadequate peritoneal toileting and faulty

1. *Dr. Muhammad Harun-Ar-Rashid, Junior Consultant \& Resident Surgeon, Sir Salimullah Medical College Mitford Hospital, Dhaka. E-mail: rashidharoon2008@gmail.com Cell Ph: +8801712642511

2. Dr. Liton Kumer Shaha, Resident Surgeon(Paediatric Surgery), Sir Salimullah Medical College Mitford Hospital, Dhaka.

3. Dr. Sanjana Sharmin Shashi, Assistant Professor, Department of Surgery, Dr. Sirajul Islam Medical College \& Hospital, Dhaka.

4. Professor Dr. Imtiaz Faruk, Department of Surgery, Sir Salimullah Medical College Mitford Hospital, Dhaka.

${ }^{*}$ For Correspondence surgical techniques in the per operative period; and wound infection (62\%), postoperative cough (28\%), abdominal distension (22\%). The result also shows that the rate of burst abdomen is still very high in SSMCMH \& DMCH and most of them occur in operations done by trainee surgeons (86\%) and in those patients who has 3 or more of the risk factors (44\%). We hope this study will arouse awareness and concern about this problem, so that more active steps will be taken for its prevention by identifying the high risk groups. This will certainly reduce the incidence of burst abdomen.

Key words: Burst abdomen, Emergency laparotomy, Risk factors.

\section{INTRODUCTION}

Burst abdomen is a serious post-operative complications in case of abdominal surgery as it carries substantial morbidity and mortality, increases the cost and hospital stay of the patient. Many patients in Bangladesh have poor nutritional status and presentation of patients with peritonitis is often delayed in the emergency. This causes more common problems of wound dehiscence. Estimates of the incidence vary between 0.5 to $6 \%$ in different studies. ${ }^{(1)}$ Burst abdomen is a multifactorial problem conditioned by local and systemic as well as pre-operative, per-operative and post-operative risk factors. The mortality with this burst abdomen has been computed by different authorities as $10 \%-44 \%$. ${ }^{(7)}$ When there is extensive suppuration of the wound, the prognosis is very grave. ${ }^{(6)}$ Good knowledge of the risk factors responsible for wound infection is mandatory for prophylaxis on the part of surgeon's technique \& OT instrument supplying authority. Many of the emergency operations are usually done by junior / trainee doctors. This may make the problem of burst abdomen more common and graver in our country.Patients identified as being high risk may be benefited from close observation and early intervention. If the risk factors can be predicted earlier, their numbers can be decreased and the incidence of burst abdomen will be lowered significantly.

Post-operative period of a patient after emergency laparotomy may be hazardous due to burst abdomen followed by prolonged hospital stay, increased morbidity and even death. This sort of morbidity and mortality can be reduced by increasing awareness and concern about this problem and accordingly taking more active steps for its prevention by identifying the high risk groups. 


\section{MATERIALS AND METHODS}

This cross sectional study was done among 100 cases of burst abdomen occurring in Sir Salimullah Medical College \& Mitford Hospital, Dhaka and Dhaka Medical college, Dhaka during the period of July, 2011 to December,2011. The purpose of the study was to find out the risk factors of burst abdomen in emergency laparotomy. The patients were admitted for various surgical problems and underwent emergency laparotomy. Burst abdomen was taken into account. Another group of 100 patients who undergone emergency laparotomy but did not develop burst abdomen were also taken into account to make a comparison with the burst group.

The case notes of the patients including age, sex of the patient, were also studied to obtain the information regarding initial complaints of the patients for admission and findings of general examination with special reference to history of COPD / bronchial asthma, nutritional status, anaemia, peritonitis, diabetes mellitus, obesity, jaundice and history of tuberculosis, exposure to radiation, use of steroids, cytotoxic drug, immunosuppressive drugs. Co-morbid factors like anaemia, diabetes mellitus, malnutrition etc. were corrected where possible.

Relevant investigations which are required for all cases were carried out; such as blood for $\mathrm{Hb} \%$, Serum creatinine, fasting blood glucose level, serum total protein and serum bilirubin, serum electrolytes, X-ray Chest and plain X-ray of abdomen etc. before operation.
The statistical significance of these clinical variables was determined by chi-square analysis. The $95 \%$ confidence interval (CI) was used to assess the significance of the differences between the groups. $\mathrm{P}<0.05$ was considered significant. The results have been arranged in a tabulated form, A comparison has been shown in the tables with the burst cases and the patients who undergone emergency laparotomy but did not develop burst abdomen. Burst cases are designated as Group A and the patients who did not develop burst abdomen are designated as Group B. S.

\section{RESULTS}

The results were prepared on 100 patients underwent emergency laparotomy in SSMCMH \& DMCH. Burst abdomen following emergency laparotomy results from multifactorial causes. The main outcome measure found significant as the risk factors of burst abdomen in this study were peritonitis (95\%), anaemia (26\%), malnutrition (18\%), in the preoperative period; inadequate peritoneal toileting and faulty surgical techniques in the per operative period; and wound infection $(62 \%)$, postoperative cough $(28 \%)$, abdominal distension (22\%). The result also shows that the rate of burst abdomen is still very high in SSMCMH \& $\mathrm{DMCH}$ and most of them occur in operations done by trainee surgeons $(86 \%)$ and in those patients who has 3 or more of the risk factors (44\%).

Table I: General Risk Factors of Burst Abdomen ( $n=100)$

\begin{tabular}{|c|c|c|c|c|c|}
\hline \multirow{2}{*}{ Factors } & \multicolumn{2}{|c|}{$\begin{array}{c}\text { Group A } \\
\text { (Patients who developed burst } \\
\text { abdomen) }\end{array}$} & \multicolumn{2}{|c|}{$\begin{array}{c}\text { Group B } \\
\text { (Patients who did not develop burst } \\
\text { abdomen) }\end{array}$} & \multirow[t]{2}{*}{ P Value } \\
\hline & $\begin{array}{l}\text { No. of } \\
\text { Cases } \\
(\mathrm{n}=100)\end{array}$ & $\%$ & $\begin{array}{l}\text { No. of } \\
\text { Cases } \\
(\mathrm{n}=100)\end{array}$ & $\%$ & \\
\hline Malnutrition & 18 & 18 & 8 & 08 & \multirow{11}{*}{$\begin{array}{c}<0.001 \\
(S)\end{array}$} \\
\hline Diabetes Mellitus & 10 & 10 & 4 & 04 & \\
\hline Malignancy & 4 & 04 & 2 & 02 & \\
\hline Jaundice & 4 & 04 & 2 & 02 & \\
\hline Uraemia & 4 & 04 & 1 & 01 & \\
\hline Steroid Therapy & 6 & 06 & 1 & 01 & \\
\hline Obesity & 8 & 08 & 4 & 04 & \\
\hline COPD / Asthma & 12 & 12 & 6 & 06 & \\
\hline Peritonitis & 95 & 95 & 90 & 90 & \\
\hline Tuberculosis & 6 & 06 & 05 & 05 & \\
\hline No risk Factors & 5 & 05 & 10 & 10 & \\
\hline
\end{tabular}

$S=$ Significant, $\quad P$ value reached from Chi square test 
Table I shows that peritonitis during admission was present in $95 \%$ cases of burst abdomen compared to $90 \%$ cases in the patients who did not develop burst abdomen. Anaemia was the next important co-morbid factor. It was present in $26 \%$ cases of burst abdomen but in $12 \%$ cases in Group B. Similarly malnutrition, obesity, jaundice, diabetes mellitus, asthma/COPD were found to play role in Group A than Group B. The differences were statistically significant.

Table II: Surgical skill of the operating surgeons $(n=100)$

\begin{tabular}{|l|c|c|c|c|c|}
\hline \multirow{2}{*}{ Grade Of Surgeons } & \multicolumn{2}{c|}{$\begin{array}{c}\text { Group A } \\
\text { (Patients who developed burst } \\
\text { abdomen) }\end{array}$} & $\begin{array}{c}\text { Group B } \\
\text { (Patients who did not develop burst } \\
\text { abdomen) }\end{array}$ & P Value \\
\cline { 2 - 6 } & $\mathrm{n}$ & $\%$ & $\mathrm{n}$ & $\%$ & \\
\hline Experts(Consultant \& above) & 14 & 14 & 36 & 64 & $<0.02 \mathrm{~s}$ \\
\hline Trainees & 86 & 86 & 64 & 64 & \\
\hline
\end{tabular}

$\mathrm{S}=$ Significant, $\mathrm{P}$ value reached from Chi square test

Table -II shows the comparison of the experience of surgeons in relation of burst abdomen. In Group A,most of the burst abdomen occurred in the hand of trainee doctors (86\%) and less $(14 \%)$ seen in the hand of Expert Surgeons compared to Group B. The difference was statistically significant $(\mathrm{p}<0.02)$.

Table III: Factors in Post-operative Period(n=100)

\begin{tabular}{|l|c|c|c|c|c|}
\hline \multirow{2}{*}{ Factors } & \multicolumn{2}{c|}{$\begin{array}{c}\text { Group A } \\
\text { (Patients who developed burst } \\
\text { abdomen) }\end{array}$} & $\begin{array}{c}\text { Group B } \\
\text { (Patients who did not develop burst } \\
\text { abdomen) }\end{array}$ & P Value \\
\cline { 2 - 5 } & $\mathrm{n}=100$ & $\%$ & $\mathrm{n}=100$ & 0 \\
\hline Wound infection & 62 & 62 & 06 & 06 \\
\hline Postoperative cough & 28 & 28 & 12 & 12 \\
\hline Abdominal Distension & 22 & 22 & 04 & 04 \\
\hline Vomiting & 14 & 14 & 06 & 06 \\
\hline Bowel leakage & 06 & 06 & 00 & 00 \\
\hline No Factors & 02 & 02 & 72 & 72 \\
\hline
\end{tabular}

$S=$ Significant, $P$ value reached from Chi square test

Table III shows that wound infection was the most frequent factor in the postoperative period and was present in $62 \%$ cases of burst abdomen which is very much higher than the group who did not develop burst abdomen. The next frequent factor was postoperative cough. Abdominal distension was present in $22 \%$ cases of burst abdomen compared to only $4 \%$ cases in Group B.Postoperative vomiting played role in $14 \%$ cases of burst abdomen. The differences in between Group A and Group B were statistically significant.

Fig I: Postoperative Day of Burst Abdomen scale.

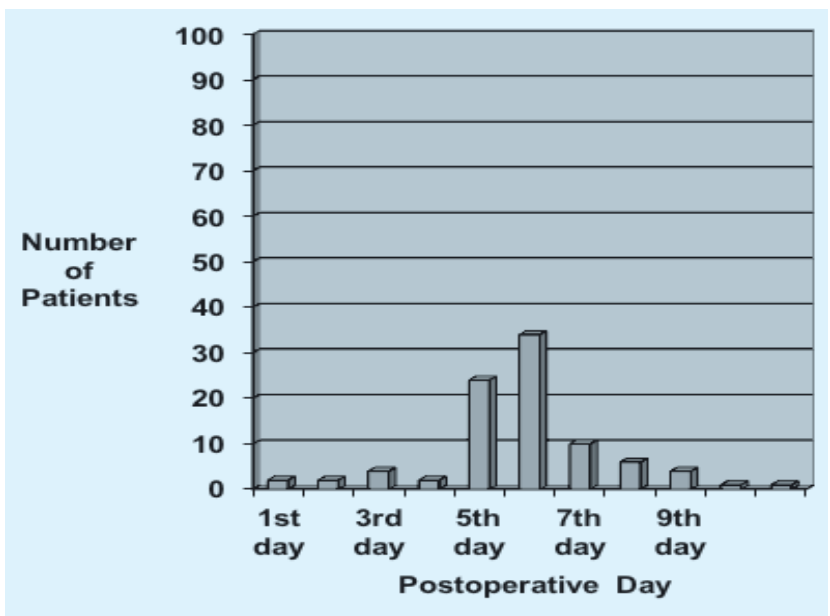

Fig-I: shows that the rate of burst abdomen is highest on 6th postoperative day (34\% cases). Maximum of the burst abdomen occurred between the 5 th -8 th postoperative day. 


\section{DISCUSSION}

In spite of advancement in surgical techniques, facilities for modern equipments and personal experiences, burst abdomen still play an important role in postoperative morbidity and mortality. Incidence of burst abdomen varies with underlying general condition, the type of operation and the presenting pathology. The peak incidences are between 6th and 8th Postoperative days.

Various factors are also involved in wound healing and in the process of burst abdomen; these predisposing factors that causes wound disruption have been studied extensively. They are classified as preoperative general causes, operative or local cause, and postoperative causes. In this series, I tried to identify factor or combination of factors that are responsible for burst abdomen.

Burst abdomen can occur in any age group. The age distribution in my series is 13 years to 70 years with peak incidence in patients at or above 50 years $(30 \%)$ cases. This correlates with the observation of Hermosa JR, et al. They found in their series $24 \%$ cases. ${ }^{15}$ Pollock AV et al found in their series $20 \%$ cases. ${ }^{16}$ Burst abdomen is more in old age group because of atherosclerotic change of blood vessels wall results in less tissue perfusion and also they are more prone to infection due to decreased immunity. Next higher incidence was in the $40-49$ years age group (24\%). This may be due to higher rate of admission of this age group in the surgical unit of this hospital.

Peritonitis during admission in the hospital was present in $95 \%$ cases of burst abdomen which was $90 \%$ in non-dehisced cases. Normally, in case of emergency laparotomy all patients have peritonitis. But, in my study, there are some cases those were diagnosed as acute appendicitis preoperatively but peroperatively those cases were diagnosed as caecal growth, ileocaecal TB, ruptured ectopic pregnancy, meckel's divertculitis with severe adhesions and stricture,congenital bands and adhesions etc. and so, decisions of emergency laparotomy were made. Peritonitis causes bacteraemia and leads to bone marrow suppression and even renal failure, respiratory failure and multisystem failure. All these complications may lead to postoperative wound infection and poor wound healing leading to burst abdomen.

In my series, anaemia was associated with burst abdomen in $26 \%$ as compared to only $14 \%$ cases in Group B. In their study Hermosa JR et al found that anaemia was associated with $24 \%$ cases. $^{15}$ Barbhuyan MA in his series found anaemia with wound dehiscence in $26 \%$ cases. $^{8}$ Anaemia contributes wound dehiscence by producing hypoxic effect at healing area.

In the present study malnutrition is found in $18 \%$ cases. It is quite similar to previous study done by Irvin $\mathrm{T}$ et al found in their series malnutrition $18 \%$ cases. $^{18}$ Malnutrition contributed to dehiscence by the defective synthesis of collagen, ground substance at the site of wound healing.

Diabetes mellitus was found in $10 \%$ cases. In the series by Barbhuyan MA diabetes was present in $8 \%$ cases. ${ }^{8}$ Diabetes mellitus causes microangiopathy, atherosclerosis and increased susceptibility to infection and thus causes wound dehiscence as well as burst abdomen.

Jaundice was present in $4 \%$ cases of burst abdomen in comparison to $2 \%$ cases in the non-dehisced cases. This is dissimilar to the study done by Pollock AV et al . They found in their series jaundice in $11 \%$ cases. ${ }^{16}$ Irvin et al found in their series in $14.6 \%$ cases. ${ }^{18}$ This dissimilarity may be due to my study limitation, a small number of cases selected for study done by me but on the other hand they have done their study on a large number of patients.

In this study, $6 \%$ cases had history of steroid intake for bronchial asthma and previously diagnosed tuberculosis. This is supported by Busti AJ et al. In their series $8 \%$ patients took corticosteroids. ${ }^{19}$

Obesity was present in $8 \%$ cases of my study. In a study, Pollock AV et al found obesity in $11 \%$ of cases ${ }^{16}$ and in study done by Bucknall $\mathrm{T}$ et al obesity was found in 15\% cases. ${ }^{17}$

Faulty surgical technique is one of the important local factors for burst abdomen. In my series most of the burst abdomen occurred in the hand of trainee doctors $(86 \%$ cases) and lesser percentage in operarions done by Expert surgeons $(14 \%$ Cases) in comparison to $36 \%$ cases done by experts and $64 \%$ done by trainee in Group B. In the study done by Barbhuyan $\mathrm{A}$ in his series trainee doctors are $52 \%$ cases and professor $14 \%$ cases. ${ }^{8}$ Bucknall $\mathrm{T}$ et al found in their series wound dehiscence in the hand of trainee doctors $50.75 \%$ cases and in the hand of experienced doctors $4.25 \%$ cases. $^{17}$

In my study, in the burst group where incisions was closed in by continuous running suture $66 \%$ was burst whereas in Group B where incision was closed by continuous running suture in $42 \%$. Continuous running suturing technique led to more burst abdomen than the group where wound was closed by continuous interlocking suture (34\%). Pollock AV et al found in their series $64 \%$ cases in continuous technique and $3.5 \%$ cases in interrupted suture technique. ${ }^{16}$ 
The result of the study shows that appearance of burst abdomen is highest in sixth post-operative day ( $34 \%$ cases ). Hadded V shown that the largest number of wound dehiscence becomes clinically evident on the 6-10th postoperative day. ${ }^{20}$ In my study most of the burst abdomen occurred also at fifth to ninth postoperative day and most of were in the 6 th postoperative day(34\%). $26 \%$ cases occurred in the 5 th post-operative day.

I observed that in most of the patients with complete wound dehiscence $(44 \%)$ had 4 or more risk factors. No single factor can said to be responsible in causing burst abdomen.

\section{REFERENCES}

1)S K Mathur,Burst abdomen,a preventable complications, monolayer closure of the abdominal incision with monofilament nylon, journal of post graduate medicine(serial online),1983, volume 29, [cited 2008 Dec 3]:29:223-9 Available from: http://jpgmonline.com/text.asp"1983/29/4/223/5514.

2)Madson G Fischer L , Burst abdomen-clinical features and factors influencing mortality. Dan Med Bull 1992;39:183-185

3)Makela JT,Kiviniemi H,Juvonen T,Laitinen S:Factors influencing wound dehiscence after midline laparotomy.Am J,1995 Surg 170:387-390.

4)Gurlyik G.Factors affecting disruption of surgical abdominal incisions in early postoperative period.Ulus Trauma. Derg 2001;7(2):96-9

5)Theodoros $\mathrm{E}$ et al Complete dehiscence of the abdominal wound and incriminatingfactors(http://www3.interscience.wile.com/jo urnal/106563828/abstract/accessed on 01/17/2010.)

6) Burger JW,Vant's Riet M,Jeekel J. Abdominal Incisions: Techniques and post operative complications.Scand J Surg 2002;91:315-21.

7) Riov JP ,Cohen JR,Johnson H Jr.Factors influencing wound dehiscence.Am J Surg 1992;13:324-330.

8)Barbhuiyan MA. Abdominal wound dehiscence. Aetiological study. 1990;3-4 (Dissertation BCPS).

9) Borley NR, Glass J, Surface anatomy of the abdomen and pelvis. In: Standring S, Ellis H, Healy JC, Johnson D, Williams A ,editors. Gray's Anatomy -the anatomical basis of clinical practice. 39th ed. Elsevier Churchill Livingstone,2005:1101-9.

10)Alistair P, Nicholas CM:Postoperative Care. In: Russel
R.C.G,Williams NS, Bulstrode, editors.Bailey and Love's short practice of surgery.25th ed.Arnold,2008:267.

11) Leaper DJ, Low L: Surgical access: incisions and the management of wounds. In: Kirk RM,Ribbans WJ.editors:Clinical Surgery in General.4th ed.Churchil Livingstone, 2004:232.

12) Afzal S,Bashir MM:Determinants of Wound Dehiscence in Abdominal Surgery in Public Sector Hospital . Annals Vol 14.No.3Jul-Sept.2008.

13) Haukipuro K,Melkko J.Connective tissue response to major surgery and postoperative infection.Eur J Clin Invest 1992;22;333.

14) Anthony LG, Peel, Sterile precaution and theater safety. In. Russel RCG, Williams N, Bulstrode GK, editors,Bailey and Loves short practice of surgery.24thed.Arnold,2005:138-42.

15)HermosoJR ,Cazader AC, Rub B, Roig J ,Pujadas M,Port J,et al. Risk factor for acute abdominal wall dehiscence after laparotomy in adult.Cir ESP Res 2005;77(5):280-6

16) Pollck AV, Greenall MJ, Evan SM. Single layer mass closure of major laparotomies by continuous suturing .Jr. Roy Soc Med 1979;72:889-93.

17)Buknall $T$, Coy $P$, Ellis $H$, Burst abdomen and incisional hernia. A prospective study of 1129 major laparotomies.Br. Med jr,1982; Vol 284:931-3.

18) Irvin T, Vassilakis J, Chattopaddhay, Greaney $M$. Abdominal wound healing in jaundiced patients.Br. J Surg 1979;65:521-22.

19)Busti AJ, Hoopper JS, Amaya CJ, Kazi S .Effects of preoperative anti-inflammatory and immunomodulating therapy on surgical wound healing. Pharmacotherapy, 2005 ;

25(ii):1566-91.

20) Haddad V, Macon WI. Abdominal wound dehiscence and evisceration :Contributing factors and improved mortality, Res 1980,Vol.46(9):508-13. 